\title{
SOLID DISPERSION - A NOVEL APPROACH FOR BIOAVAILABILITY ENHANCEMENT OF POORLY WATER-SOLUBLE DRUGS IN SOLID ORAL DOSAGE FORMS
}

\author{
PURNACHANDRA REDDY GUNTAKA*, SRINIVAS LANKALAPALLI
}

Department of Pharmaceutics, GITAM Institute of Pharmacy, GITAM University, Rushikonda, Visakhapatnam, Andhra Pradesh, India. Email: gpcreddy86@gmail.com

Received: 16 August 2018, Revised and Accepted: 24 September 2018

\begin{abstract}
Enhancement of the bioavailability of poorly water-soluble drugs is a challenging task in drug development. Currently $40 \%$ of new chemical entities are discovered as poorly water-soluble drugs. Solid dispersion is one of the best technology for improving solubility, dissolution rate, and bioavailability. Solid dispersion techniques are more useful for enhancing drug solubility for a combination of drug and inert carrier to improve wettability, reduced particle size, and converting amorphous particles. This article reviews various advantages, methods of solid dispersions, carriers used in solid dispersion, characterization, and marketed products.
\end{abstract}

Keywords: Bioavailability, Solubility, Dissolution, Carrier, Polymorphism.

(C) 2019 The Authors. Published by Innovare Academic Sciences Pvt Ltd. This is an open access article under the CC BY license (http://creativecommons. org/licenses/by/4. 0/) DOI: http://dx.doi.org/10.22159/ajpcr.2019.v12i2.29157

\section{INTRODUCTION}

Oral drug delivery is simplest, most popular, and easy route of the administration of drugs. Recently, more than $40 \%$ of active new chemical entities are identified as poorly water-soluble drugs [1,2]. After administration drug orally, it disintegrates in gastric fluids and then solubility of drug in gastric and/or intestinal fluids and then permeability takes place in the membrane of gastrointestinal track, and it reaches systemic circulation. Hence, poorly aqueous soluble drugs have critical to exhibit dissolution rate [3].

Based on the biopharmaceutical classification system (BCS), Class II and Class IV drugs have low aqueous solubility [4].

Noyes-Whitney equation gives some idea about the dissolution rate of poorly soluble compounds which might be improved to minimize the limitations of oral availability [5].

$\mathrm{Dc} / \mathrm{Dt}=\mathrm{AD}(\mathrm{Cs}-\mathrm{C}) / \mathrm{h}$

Where Dc/Dt is dissolution rate,

A is dissolution surface area,

D is compound diffusion coefficient,

Cs is the solubility of compound,

$\mathrm{C}$ is concentration of drug in time $t$

$\mathrm{h}$ is thickness of diffusion layer in dissolving compound.

Solid dispersion has been the most efficient technique to improve the solubility, dissolution rate, and oral absorption of poorly aqueous soluble drugs [6].

Solid dispersion is defined as a dispersion of one (or) more active ingredients in inert carrier at solid state preparation using various solid dispersion techniques [7].

The mechanism to enhance solubility by solid dispersion technique involves complete removal of dry crystallinity of poorly soluble compound in a inert carrier. Prepared solid dispersion material is exposed to aqueous media; the carrier dissolves in media and the drug is releases as fine colloidal particles. This will increases the surface area of drug particles and improve dissolution rate [8]. Drug in soluble hydrophilic carrier improves the dissolution rate by reducing particle size and increasing the particle porosity. The drug converts into crystalline form to amorphous state and improves wettability and dissolution of poorly water-soluble drugs. For better dissolution rate, purpose surfactant has been included. Surfactants are useful for better dissolution rate purpose. Surfactants are also helpful to avoid recrystallization and enhances potentiality of their solubility [9]

\section{ADVANTAGES OF SOLID DISPERSION}

Reduced particle size by increased surface area

Particle size is majorly impact on dissolution rate, especially low soluble drugs. Due to reduced particle size of drug, it may lead to increase in surface area and contact of more surface area to dissolution media. Hence, it results in more dissolution rate.

\section{Improved wettability of drug particles}

Due to increase wettability of drug particles leads to improve solubility of drug in dissolution media. The use of carriers with or without surface active agents increases drug wettability. Carriers enhance drug solubility in dissolution media due to increased wettability of drug particles.

Particles with high porosity

By use of solid dispersion technique, The carriers are having high degree of porosity. carriers are useful to increases in porosity of drug particles which results improves solubility. For example, hypromellose and some of polymers have a high degree of porosity in nature. Hence, it enhances the solubility of drug in dissolution media and it leads to high dissolution rate compared to initial drug particles.

\section{Drug particles polymorphic state}

Polymorphic form of drug particles plays a major role in drug solubility in dissolution media. Crystalline nature of drug particles has less solubility comparative to amorphous drug particles. Crystalline polymorphic form of drug particles requires more energy to break the crystalline lattice, whereas amorphous drug particles require less energy to break the particles. Using additional surface active agents, it will more useful for the enhancement of solubility in dissolution media.

\section{Solid dispersion}

Based on solid-state structure and carriers, solid dispersions are classified into different ways. Solid dispersion was performed using 


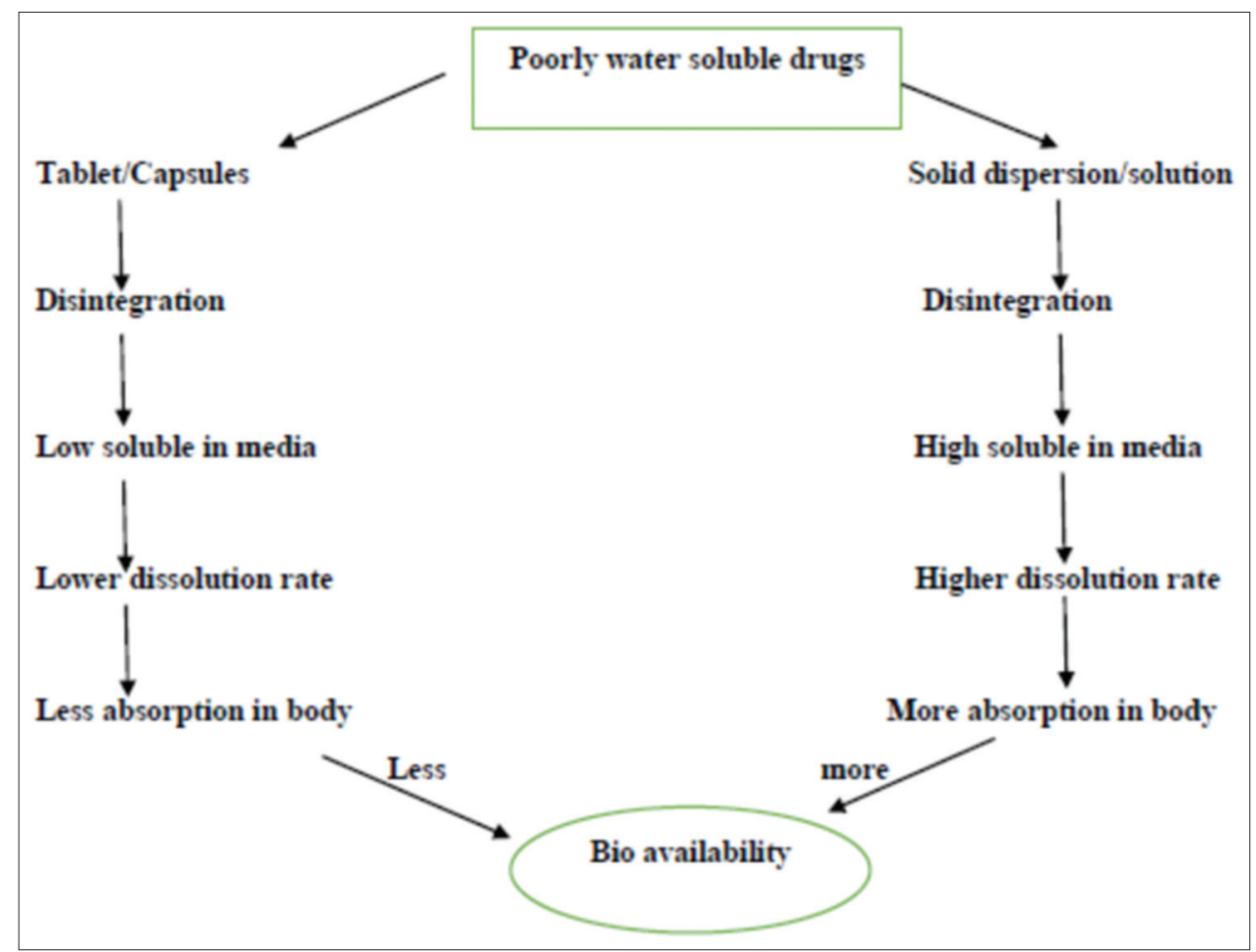

Fig. 1: Schematic representation of aqueous soluble drug

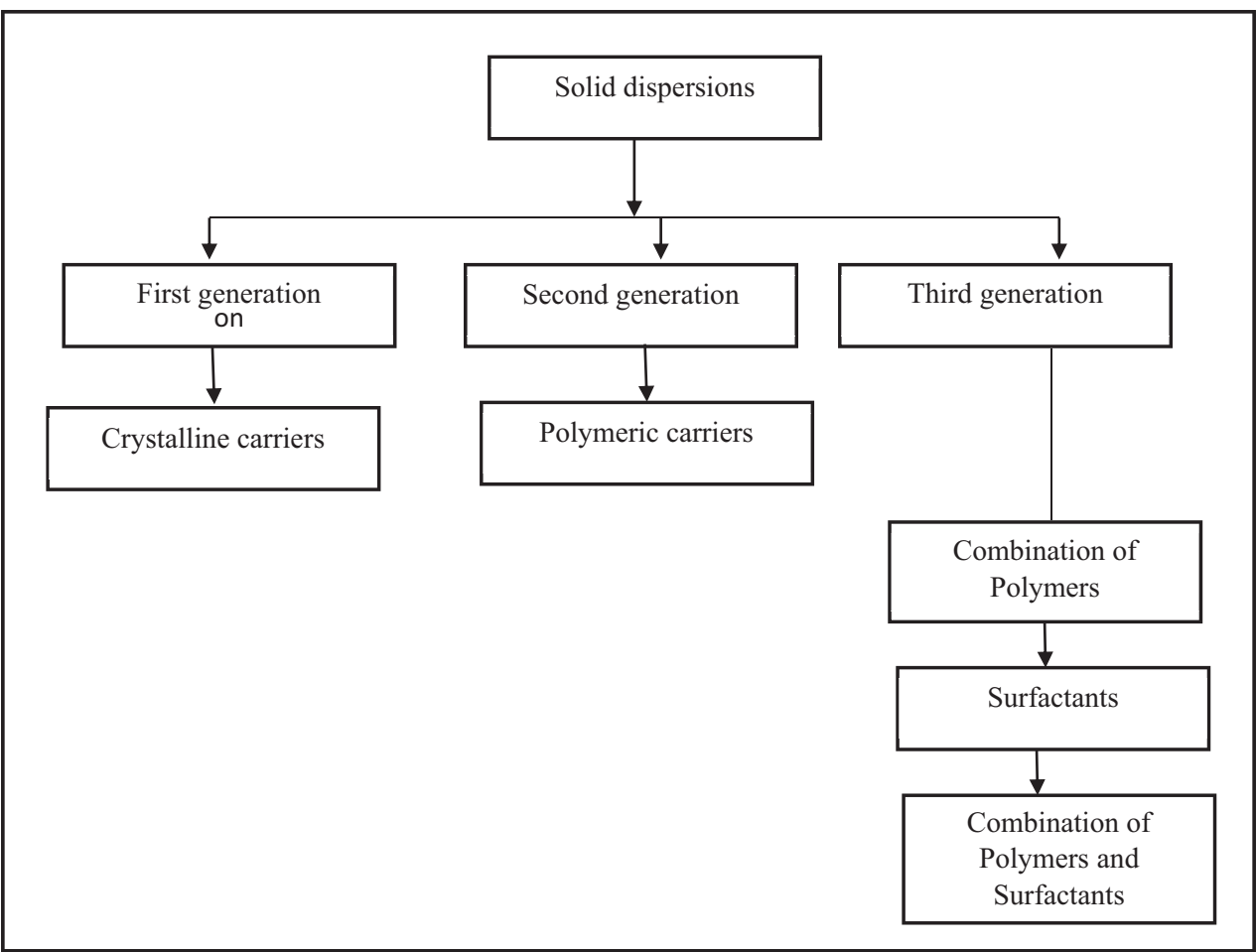

Fig. 2: Classification of solid dispersion on the basis of carrier used

different methods based on molecular structure and nature. To enhance the solubility of active pharmaceutical ingredient (API), various preparations of solid dispersions were used based on principle and mechanism. Riegelman and Chiou classified solid dispersions into the following six representative types: Amorphous precipitations in a crystalline carrier, simple eutectic mixtures, solid solutions, glass solutions and glass suspensions, compound or complex formation, and combinations of the previous five types. Given below is the classification of solid dispersion on the basis of carrier used and solid structure [10].

\section{First generation}

In the first generation, solid dispersions was developed by crystalline carriers. In general, the crystalline carriers such as sugar and urea are used. The crystalline carriers are thermodynamically more stable. But the disadvantage is some of drugs are not suitable with 
crystalline carriers its cannot release the drug in dissolution media because of crystalline nature of API. In this crystalline carriers unable to convert drug nature from crystalline to amorphous. By presence of crystalline nature of drug it leads to low solubility and bio availability $[11,12]$.

\section{Second generation}

The second-generation solid dispersions are used as amorphous carriers instead of crystalline carriers like polymers. When compared to the first generation, second-generation carriers are more helpful by converting drug in amorphous nature, which was more useful for drug solubility in dissolution media. Different polymers such as polyvinylpyrrolidone (PVP), hydroxypropylmethyl cellulose (HPMC), polyethylene glycol (PEG), and HPMC. Using these polymers, the drug nature was converted and improves in bioavailability $[13,14]$.

\section{Third generation}

Nowadays, the third-generation solid dispersions are used continuously for improving better solubility purpose. In this third generation, both the combination of surfactant and polymers and combination of polymers were used. It will more helpful for converting drug crystalline nature to amorphous nature and improved solubility in dissolution media because of surfactant. In this third generation solid dispersion technique is most effective to enhance solubility and bio availability of poorly water soluble drugs $[15,16]$.

\section{Preparation of solid dispersions}

Many methods are used for the preparation of solid dispersion systems, and some of them are enlisted as follows:

1. Spray drying

2. Hot melt extrusion method

3. Solvent evaporation method

4. Fusion/melting method

5. Melting solvent method

6. Lyophilization techniques

7. Melt agglomeration process

8. Electrospinning method

9. Supercritical fluid technology.

\section{Spray drying}

Spray drying technique is one of the most effective and commonly used solid dispersion methods. It is a single step, convenient, and easy to reproducible process. Mainly principle involved in spray dry technique is continuous transformation of converting material from liquid state to solid state using a heat drying chamber. In this process drug, polymer, sometimes surfactants, dissolves in solvent and continuous spraying in heating chamber where solvent is evaporated and converted into solid state [17].

In this drying chamber, solvent is sprayed using atomization air. The solvent is converted into fine droplets due to atomization air and converts solid particles in drying chamber.

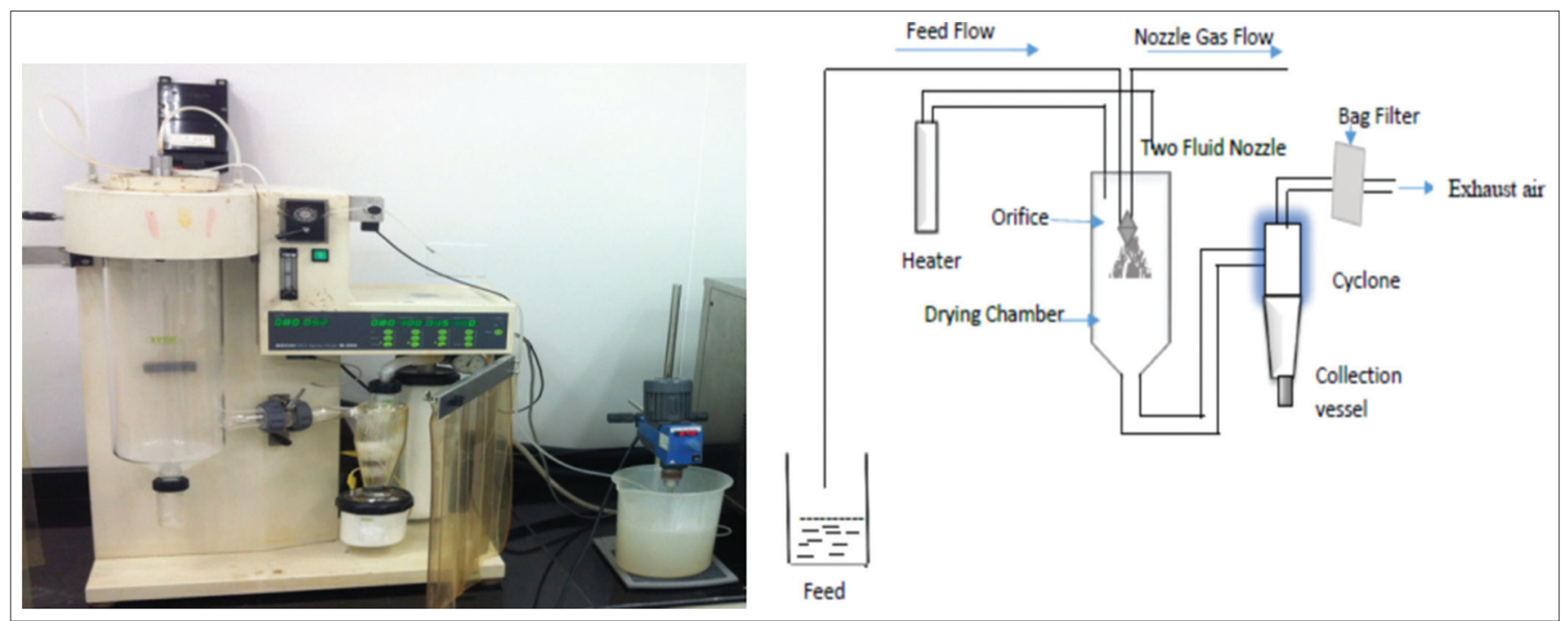

Fig. 3: Schematic diagram of spray dryer

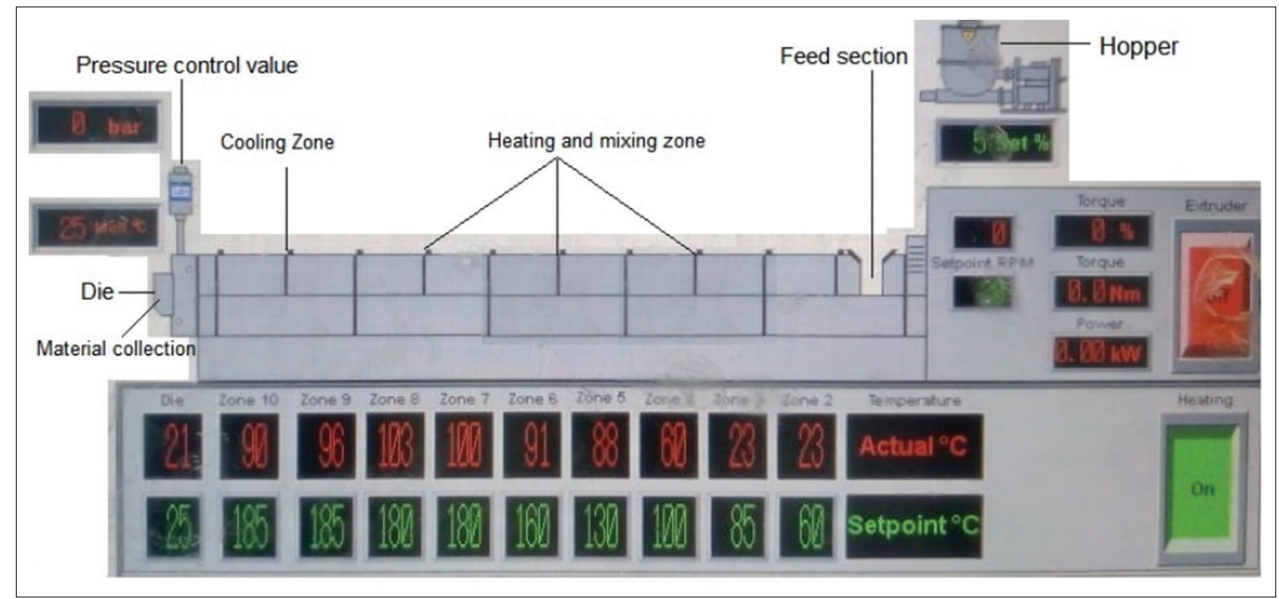

Fig. 4: Schematic diagram of hot melt extrusion 
In this technique, drug and inert carriers were complete dissolve in suitable solvent. The solvent used was single solvent or mixture of solvents based on the solubility of drug and inert carriers. Due to the solubility of drug and inert carriers, drug particles converted its crystalline nature to amorphous nature and it improves the solubility and bioavailability.

Polymers generally used as PVP, copovidone, HPMC, hydroxy propyl cellulose, and Soluplus surfactants as sodium lauryl sulfate, docusate sodium, and polysorbates. The drying chamber temperature was selected based on boiling point of solvents used. Different solvents are having various boiling points [18].

\begin{tabular}{ll}
\hline Solvents & Boiling point \\
\hline Water & $100^{\circ} \mathrm{C}$
\end{tabular}

Acetone

$56^{\circ} \mathrm{C}$

Ethanol $\quad 78^{\circ} \mathrm{C}$

Dichloromethane $\quad 40^{\circ} \mathrm{C}$

Methanol $65^{\circ} \mathrm{C}$

Hot melt extrusion method

Recently, hot melt extrusion method is more popular due to most of the formulation focusing in this technique to improve the solubility of poorly soluble drugs. The advantage of hot melt extrusion is less process time, effective technique of converting crystalline polymorphic form to amorphous polymorphic form. The main selection of hot melt extrusion technique rather than spray drying technique due to very less solubility of drug in solvent will require more solvent for dissolving drug in media. In this technique, there was no need of solvent. Hence,

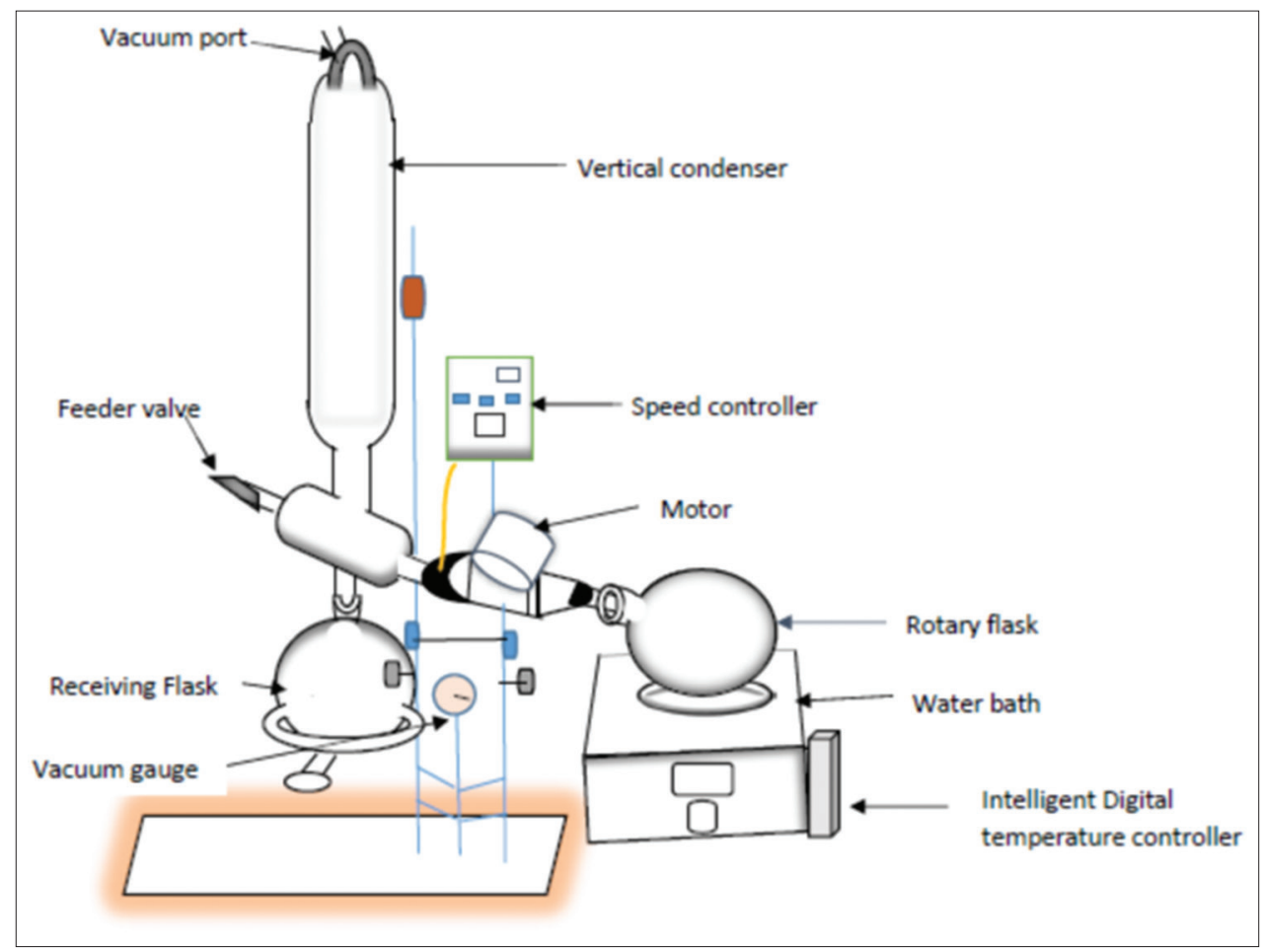

Fig. 5: Schematic diagram of solvent evaporation technique

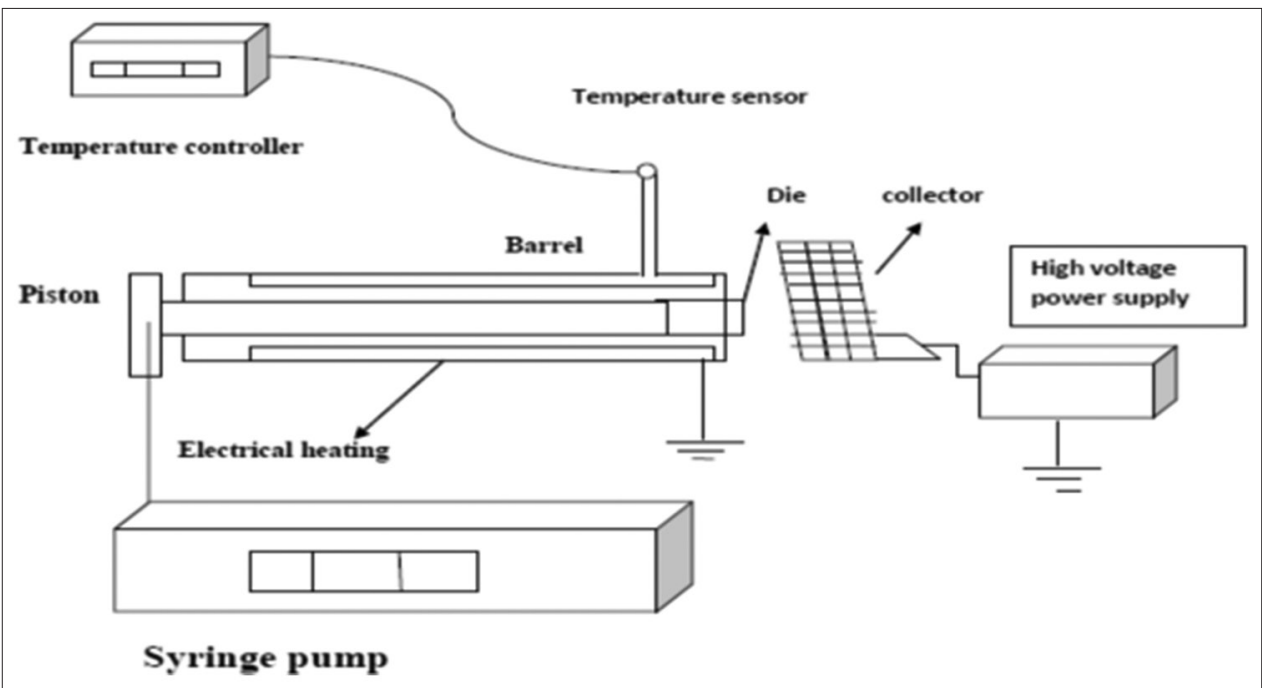

Fig. 6: Schematic diagram of melting solvent technique 


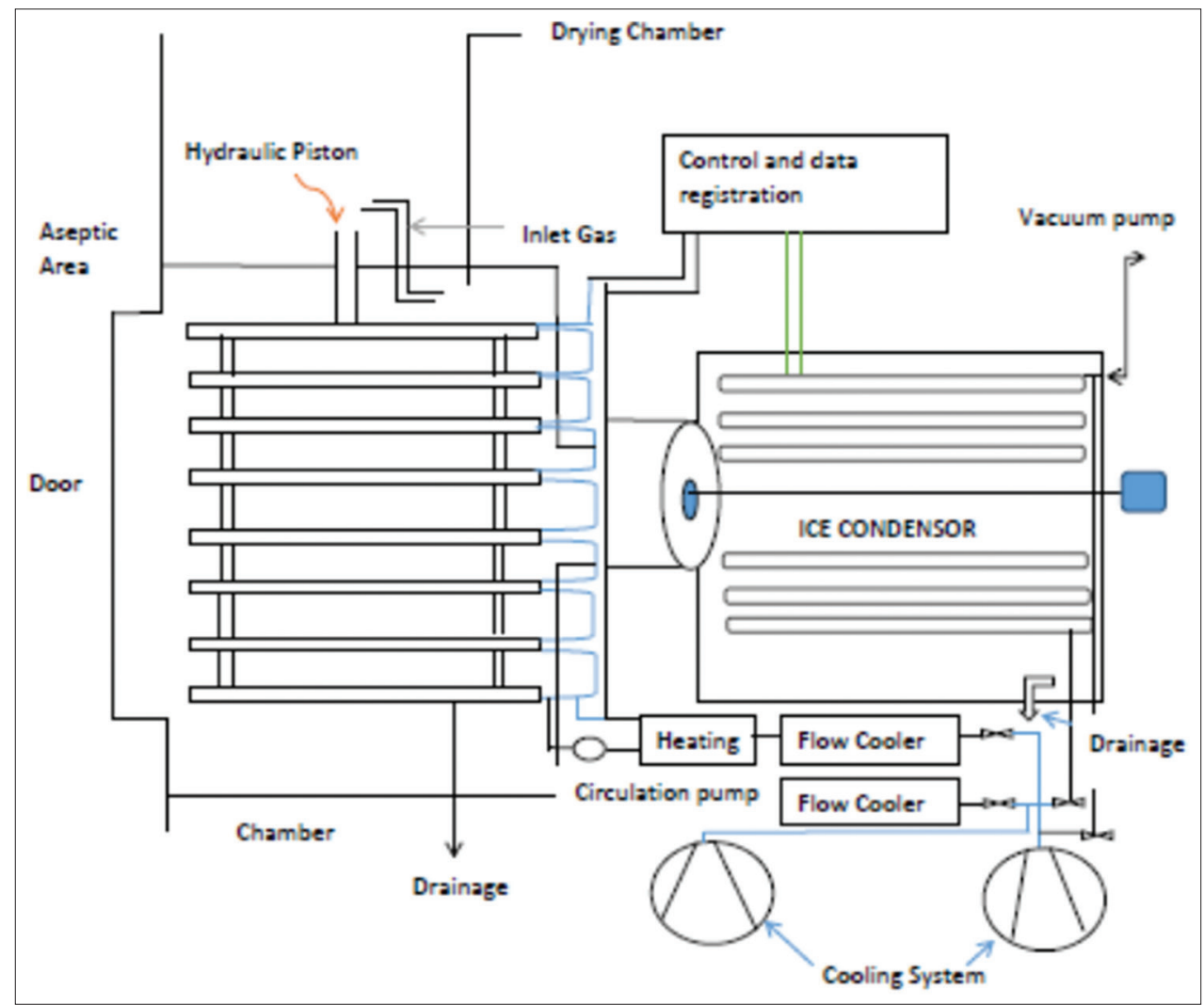

Fig. 7: Schematic diagram of lyophilizer technique

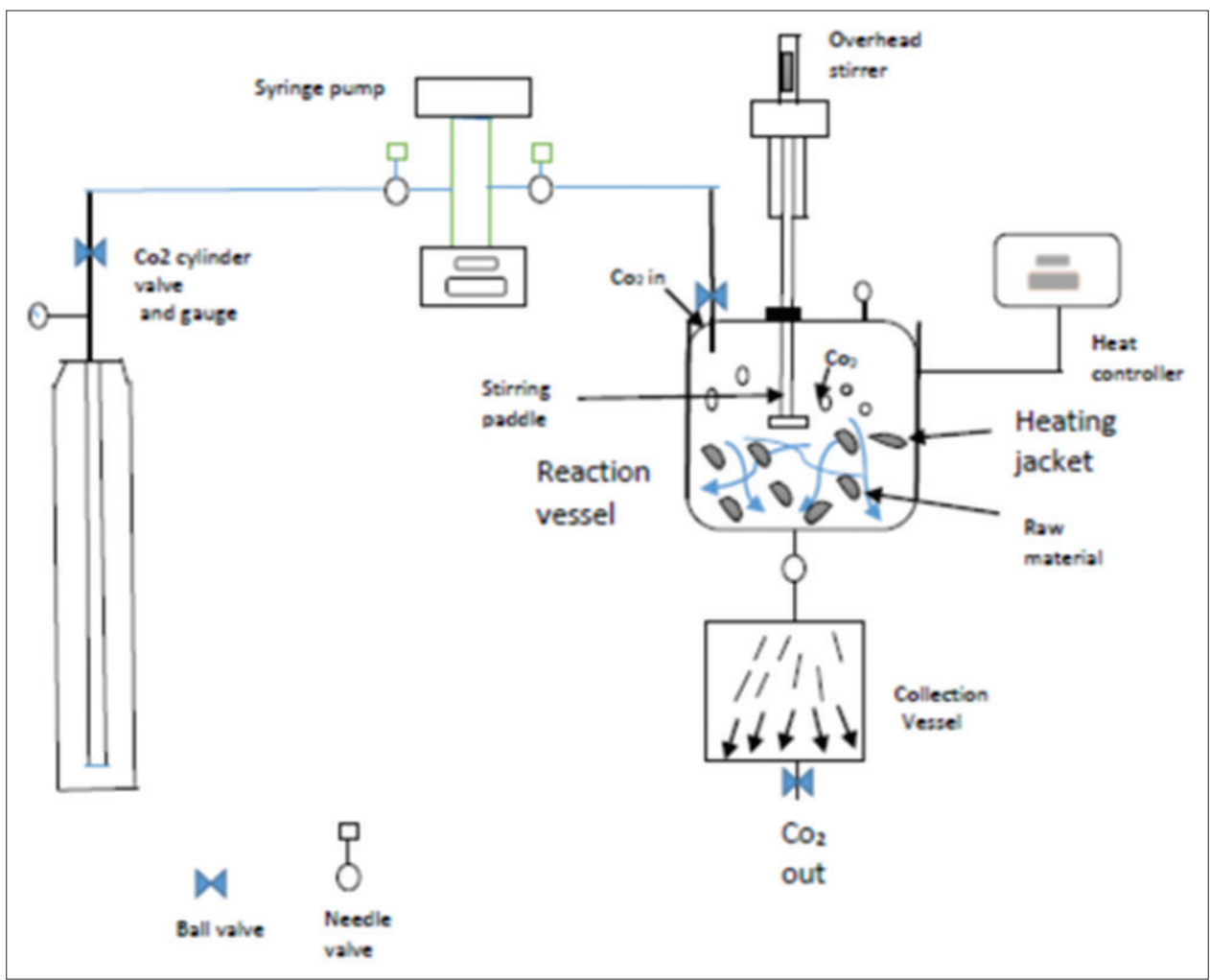

Fig. 8: Schematic diagram of supercritical fluid technique

depending on physicochemical property of drug, molecular hot melt technique was selected [19].

Hot melt extrusion is a continuous process to apply heat and pressure to melt a drug and polymer mixture in different heating chambers.
Finally, the melted mixture reaches cooling chamber and it converts into solid flakes. Melting reaches up to glass transition temperature ( Tg) of polymeric material. The selection of polymers depending on drug melting point [20]. 


\begin{tabular}{ll}
\hline Ingredients & Melting temperature \\
\hline Co povidone & $140^{\circ} \mathrm{C}$ \\
Polyvinylpyrrolidone & $150^{\circ} \mathrm{C}$ \\
Hypromellose & $190-200^{\circ} \mathrm{C}$ \\
Soluplus & $150^{\circ} \mathrm{C}$ \\
Polyethylene glycol & $37-48^{\circ} \mathrm{C}$ \\
\hline
\end{tabular}

\section{Solvent evaporation method}

In general, rotavapor is used for solvent evaporation method. In this method, drug and polymer dissolve in common organic solvent and the solvent is evaporated at low temperature. Then, the resulting mixture is milled through suitable screens. Some of the products are not suitable in this technique because only single solvent is utilized in this process. If drug is soluble in one solvent and polymer is dissolved in another solvent at the time of evaporation, solvents are evaporated based on boiling point, so drug or polymer solidified quickly based on the solvent used. It will lead to not complete polymorphic conversion occurs. So finally creates a low soluble and low dissolution rate. Hence, drug and polymer dissolve in single solvent only. The selection of polymer is based on drug nature and solubility of drug in organic solvent. In general, solvents used ethanol, acetone, isopropyl alcohol, and dichloromethane. [21,22].

\section{Fusion/melting method}

In this process melting of drug with inert carrier at particular temperature, it produces the waxy type material by combined of drug particles with inert carrier. Then, waxy material placed in cooling chamber and milling through suitable screen. The main disadvantage is drugs which are having temperature sensitive or low melting point not suitable in this technology. In general, melt granulation through rapid mixer granulation is used in this method. In this process, heat is produced continuously in outside of the chamber and inside of chamber drug, and the drug and carrier rapid mixing takes place at certain time, it converts waxy type material. Later, cool water is circulated outside of chamber, it converts solid mass, and then, it places to milling and mixing [23,24].

\section{Melting solvent method}

Melting solvent method is a combination of both processes at a time, i.e., melting and solvent evaporation method. In this technology, drug is dissolved in suitable solvent after getting clear solution directly incorporated into melt of suitable carrier. Then, continuous low heat circulated in outside until the complete solvent is evaporated. The resulting residue is the combination of drug and inert carrier then solidified it properly [25]. The solid material is milled with suitable screen and mixed with other excipients. The main advantage of this method is drugs which are having low melting and high temperaturesensitive drugs which are suitable in this method [26,27].

\section{Lyophilization techniques}

It is also called as freeze-drying in this process drug, and inert carrier dissolves in common solvent. The solution is frozen and sublimation under vacuum. The frozen state material is placed in low air pressure and it converts in glassy-like structure. The advantage of this process is minimal thermal stress and risk of phase separation is low. It is a technology that the drug substance maintains quality and stable $[28,29]$.

\section{Table 1: Solubility criteria as per USP and BP descriptive term part of solvent required per part of solute}

\begin{tabular}{ll}
\hline Very soluble & $<1$ \\
Freely soluble & From 1 to 10 \\
Soluble & From 10 to 30 \\
Sparingly soluble & From 30 to 100 \\
Slightly soluble & From 100 to 1000 \\
Very slightly soluble & From 1000 to 10000 \\
Practically insoluble & 10,000 and over \\
\hline
\end{tabular}

\section{Melt agglomeration process}

In this technology, drug and polymer or binder is placed in continuous mixing chamber. Then generates heat based on the melting point of drug. then drug and inert carrier mixing together and formulates a agglomerates. In this process find particles are melted together and forms a agglomerates. By enhancing dissolution rates use surfactants also. In this method resulting flowable material obtains to increases flow properties $[30,31]$.

\section{Electrospinning method}

This is a nanotechnology majorly used for polymer industry. In this method, a liquid stream of drug and polymer solution involves into potential between 5 and $30 \mathrm{Kv}$. When electric forces overcome to surface tension of drug and polymer solution at air interface, it involves the strong electrostatic field over a polymer solution to form a submicron diameter fibers [32]. The fiber diameter completely depends on dielectric constant, surface tension, electric field strength, and feeding rate $[33,34]$

\section{Supercritical fluid (SCF) technology}

Using SCF technology to prepare solvent free dosage forms. It is a single fluid phase above the critical temperature and pressure. Carbon dioxide is commonly used for supercritical fluid as chemically inert nature, nonflammable, and non-toxic. In this process, drug particles soluble with supercritical fluid and then recrystallization with reduced particle size as per requirement. The carbon dioxide is used for anti-solvent purpose $[35,36]$.

\section{CARRIERS USED IN SOLID DISPERSION [37]}

\section{PVP}

PVP is used in a different pharmaceutical formulation mainly solid oral dosage forms. It is a fine, odorless, white to creamy white-colored hygroscopic material. It is available in different grades divided in its $\mathrm{K}$-value. Based on molecular weight, $\mathrm{K}$ value available. $\mathrm{K}$-value is from 12 to 120 having molecular weight of $2500-3,000,000$. Melting point of $\mathrm{PVP}$ is $150^{\circ} \mathrm{C}$.The solubility is freely soluble in water, acids, chloroform, methanol, and ethanol. The viscosity of aqueous solubility depends on its molecular weight and concentration used $[38,39]$.

\section{Copovidone}

Copovidine is commonly used as a carrier of spray dry technology due to its low viscosity and better binding property. The description of copovidone is a white to yellowish white color, and it is slightly have odor component. The melting point of copovidone is $140^{\circ} \mathrm{C}$ and it is a stable component. The $\mathrm{Tg}$ of copovidone is $106^{\circ} \mathrm{C}$. Due to low-temperature glass transition nature, it is used as hot melt extrusion technology also. The solubility of copovidone is freely soluble in water, glycerol, PEG 400, and ethanol. The viscosity is $<10 \mathrm{mPas}$ at a concentration $<10 \%[40]$.

\section{HPMC}

It is also called as hypromellose. It is widely used in many pharmaceutical dosage forms in different ways due to its viscosity ranges. The description of hypromellose is white to creamy white fibrous material of odorless, and it is hygroscopic in nature. It is available in various viscosity ranges of very low viscosity $3 \mathrm{mPas}$ to high viscous range of $200,000 \mathrm{mPas}$. The melting point is about $190-200^{\circ} \mathrm{C}$ and $\mathrm{Tg}$ is $170-180^{\circ} \mathrm{C}$. the solubility of hypromellose is soluble in cool water and $\mathrm{n}$ hot water, ethanol, ether, and dichloromethane. Hypromellose is repeatedly used as a carrier in hot melt technology for conversion of crystalline polymorphic form to amorphous polymorphous form which was useful for improving solubility [41,42].

\section{Hydroxypropyl cellulose (HPC)}

HPC is an cellulose where some of the hydroxyl groups of the cellulose have hydroxyl propylated forming groups. It is a white to slightly yellow-colored odorless powder. HPC is commonly available in different grades depending on its viscosity. The viscosity ranges from 50,000 to $1,250,000 \mathrm{mPas}$. It is 
a stable molecular having melting point $130^{\circ} \mathrm{C}$. The solubility of HPC is freely soluble in water, soluble 1 in 10 parts dichloromethane, and 1 in 2.5 parts in ethanol. The pH of HPC is 5.0-8.0 [43].

\section{PEG}

PEG is a hydrophilic substance. It is available in different grades based on different molecular weights of PEG 200-8000 having molecular weights 190-9000. It is available in both liquid form and solid forms up to grade PEG 400 which are liquid materials. The description of PEG liquid grades is clear slightly yellow color and solid PEG is off-white in color. It is having very low melting point of $37-48^{\circ} \mathrm{C}$. Due to its very low melting, nature may have stability problems. The solubility of PEG is freely soluble in water, glycerine, acetone, and alcohol [44,45].

\section{Soluplus}

Soluplus is a graft copolymer it contains combination of polyvinyl caprolactam, polyvinyl acetate, and PEG. The description of Soluplus is white to slightly yellowish granules. It is a hydrophilic carrier polymer majorly designed for poorly soluble drugs. The advantage of Soluplus improves solubilization property and enhances bioavailability. Due to its excellent extrudability, it is mainly used as a hot melt extrusion process to improve solubility. The solubility of Soluplus is freely soluble in water, acetone (up to $50 \%$ ), and methanol (up to $45 \%$ ). The $\mathrm{Tg}$ is $70^{\circ} \mathrm{C}$.

\section{Carboxymethyl cellulose}

The carboxymethyl cellulose is a stable, hygroscopic substance and description is white to almost white odorless granular powder. It is available in different viscosities of low to high $(10-12,000)$. It is practically insoluble in water and melting point also high $220^{\circ} \mathrm{C}$. It has both binder and disintegrate properties [46,47].

\section{Eudragits}

Eudragits are regularly used in pharmaceutical solid oral dosage forms containing synthetic cationic and anionic polymers. It is also called as polymetha acrylates. It is available as different stages (dispersion, solid, and organic solutions) and different grades are having different applications based on $\mathrm{pH}$ dependent and $\mathrm{pH}$ independents. Typically, the molecular weight of polymer is above 100,000 . Eudragit $\mathrm{E}$ is soluble in gastric fluids about $\mathrm{pH}$ 5 , Eudragit $\mathrm{L}$ is soluble in above 6 , and Eudragit $\mathrm{S}$ are soluble in above $\mathrm{pH}$ 7. Eudragit RL are forms water-insoluble film and are more permeable than those of Eudragit RS. The solubility of eudragits is a mixture of organic solvents isopropyl alcohol, acetone, and water [48].

\section{Hypromellose acetate succinate}

Hypromellose acetate succinate is a white to off-white powder and available in several grades according to the $\mathrm{pH}$ at which polymer dissolves (low - L, medium - M, and high - $\mathrm{H}$ ). the molecular weight is approximately $55,000-93,000 \mathrm{Da}$. It is a solubility-enhancing agent through solid dispersion and is insoluble in gastric fluid but will swell and dissolve rapidly in the upper intestine. The $\mathrm{Tg}$ is $113^{\circ} \mathrm{C}$. The solubility is a mixture of ethanol and dichloromethane in 1:1 ratio [49].

\section{Hypromellose phthalate}

Hypromellose phthalate is a white to slightly off-white freely flowing flakes granular odorless powder. Hypromellose phthalate is a cellulose in which some of the hydroxyl groups are replaced with methyl esters. Different types of hypromellose phthalate are commonly available with molecular weight in a range of $80,000-130,000 \mathrm{Da}$. It is a hygroscopic material having $\mathrm{Tg}$ of $137^{\circ} \mathrm{C}$ and melting point of $150^{\circ} \mathrm{C}$. The solubility is a mixture of acetone and methanol or ethyl alcohol 1:1 ratio [50].

\section{Acids}

In general, acids are high soluble components and are used as $\mathrm{pH}$ modifiers in pharmaceutical dosage form which was useful for $\mathrm{pH}$ sensitive molecules. Mainly citric acid monohydrate and tartaric acid are commonly used in the formulation. These are transparent crystalline, hygroscopic nature. The low melting point acids are converts into soften in nature. Different grades are available based on particle size difference [51].

\section{Sugars}

Simple sugars are named as monosaccharides which include sucrose, dextrose, glucose, and fructose. A part from this sugar alcohol is available which is called as polyols including sorbitol, mannitol, and xylitol. Sugars are high soluble hygroscopic substances. The melting point range is $160-186^{\circ} \mathrm{C}$. Sugar alcohols are freely soluble non-hygroscopic substances. These are commonly used as solid oral dosage forms as a plasticizer and diluent. Compared to sugars, sugar alcohols are stable substances. The common melting range is $166-168^{\circ} \mathrm{C}$. it is suitable as moisture-sensitive active ingredients due to its non-hygroscopic nature [52].

\section{Surfactants}

Surfactants play a major role in pharmaceutical products. Surfactants are surface active agents which reduce surface tension. It improves the wettability of solid surface of drug particles it leads to improved solubility. In solid dispersion technology surfactants used for combination of polymers because it enhances solubility, dissolution rate and improves the bioavailability. It is classified into four types: Anionic, nonionic, cationic, and amphoteric surfactants [53].

\section{Anionic surfactants}

It dissolves in water negatively charged particles created. Sodium lauryl sulfate is anionic surfactant commonly used in formulations.

\section{Cationic surfactants}

It dissolves in water positive-charged particles created. Quaternary ammonium salts and amines with amide linkages are some of the examples of cationic surfactants.

\section{Non-ionic surfactants}

It contains hydrophilic groups. Tweens and spans are common examples of non-ionic surfactants.

\section{Amphoteric surfactants}

These are also called as zwitterionic surfactants and it contains both anionic and cationic centers attach to the same molecular. Examples are sodium dodecyl sulfates phospholipids.

\author{
Characterization of solid dispersions [54-78] \\ 1. Physical appearance \\ 2. Drug content \\ 3. Dissolution \\ 4. Electron microscopy \\ 5. X-ray powder diffraction (XRD) studies \\ 6. Fourier transform infra red (FTIR) spectroscopy \\ 7. Differential scanning calorimetry (DSC).
}

\section{Physical appearance}

It involves the appearance of solid dispersion by visual inspection.

\section{Drug content}

It is a analysis of the amount of drug present in solid dispersion. The assay method of drug is taken and dissolved in suitable solvents which ensure that freely soluble in nature and dilute it in appropriate concentration. Finally drug content measured by UV or high performance liquid chromatography (HPLC) method.

\section{Dissolution}

Dissolution measures the dissolve component at particular time period. The percentage of drug release at particular time period measured by basically UV or HPLC methods. The study is performed at predetermined volume and RPM at $37 \pm 0.5^{\circ} \mathrm{C}$. As per USP 7 dissolution apparatus are available. Commonly, basket or paddle apparatus is used 
Table 2: Solid dispersion technology used in marketed products $[\mathbf{7 9 , 8 0}]$

\begin{tabular}{lll}
\hline Product name/substance & Technology used & Company \\
\hline UROCIT-K/Potassium citrate & Melt granulation & Mission Pharmacal Co \\
KALETRE/Lopinavir and Ritonavir & Hot melt extrusion & ABBVIE INC \\
Intelence/Etravirine & Spray drying & Janssen Research and Development \\
Sporanox/Itraconazole & Spray layering & Janssen Pharmaceuticals \\
Gris-PEG/Griseofulvin & Melt process & Valeant Pharmaceuticals \\
Zortress/Everolimus & Spray drying & Novartis Pharmaceuticals \\
Zelboraf/Vemurafenib & Coprecipitation & Hoffmann-La Roche \\
Kalydeco/Ivacaftor & Spray drying & Vertex Pharmaceuticals \\
Orkambi/Ivacaftor; Lumacaftor & Spray drying & Vertex Pharmaceuticals \\
\hline
\end{tabular}

for solid oral dosage forms.

\begin{tabular}{|c|c|c|}
\hline USP app & Description & Dosage forms \\
\hline Apparatus I & Basket & $\begin{array}{l}\text { Conventional, chewable } \\
\text { and controlled-release } \\
\text { tablets, capsules }\end{array}$ \\
\hline Apparatus II & Paddle & $\begin{array}{l}\text { Conventional tablets, ODT, } \\
\text { ER }\end{array}$ \\
\hline Apparatus III & Reciprocating cylinder & CR and chewable tablets \\
\hline Apparatus IV & Flow-through cell & $\begin{array}{l}\text { ER, poorly soluble } \\
\text { API formulations, } \\
\text { microparticles, implants }\end{array}$ \\
\hline Apparatus V & Paddle over disk & Transdermal \\
\hline & Cylinder & Transdermal \\
\hline Apparatus VII & Reciprocating holder & $\begin{array}{l}\text { CR (non-disintegrating oral } \\
\text { and transdermal) }\end{array}$ \\
\hline
\end{tabular}

\section{Scanning electron microscopy}

It is used to find the images of sample by scanning to surface of material with focused beam. Electron microscopy is helpful to morphological structure of material.

\section{XRD studies}

Powder XRD studies play a major role for identifying polymorphic forms, i.e., crystalline or amorphous. Based on diffracted beam angles and intensities of molecular structure to particular drug components 2 theta values occurs.

\section{FTIR spectroscopy}

FTIR spectroscopy gives a clear picture of interaction between drug to drug and drug to excipients. It measures intensity over a narrow range of wavelengths at a time.

\section{DSC}

DSC is a thermoanalytical technique which measures endothermic and exothermic reactions by increasing temperature gradually. Endothermic reactions measure melting and boiling points. Exothermic reactions measure crystallization and polymerization (Table 2).

\section{CONCLUSION}

Solid dispersion system is extremely useful for improving solubility and dissolution rate of poorly water solubility drugs, i.e., BCS Class II and IV drugs. The various solid dispersion techniques described above are useful to improves the solubility of drug substance. Based on drug nature, the selection of solid dispersion method is required for the enhancement of bioavailability. Drug is exposed to carrier in the presence of solvent the resultant mixture which is fine colloidal particles to produce higher bioavailability. It can significantly increase porosity and wettability properties of drug. Sometimes, surfactants are also useful for better improvement of dissolution rate. For higher solubility rates, optimization of polymer and surfactant concentration is required.

\section{AUTHORS' CONTRIBUTIONS}

Thanks to Dr. Srinivas Lankalapalli for helping review, final corrections, and approved the final version of the manuscript.

\section{CONFLICTS OF INTEREST}

The authors declared that they have no conflicts of interest.

\section{REFERENCES}

1. Youn YS, Jung JY, Oh SH, Yoo SD, Lee KC. Improved intestinal delivery of salmon calcitonin by lys18-amine specific PEGylation: Stability, permeability, pharmacokinetic behavior and in vivo hypocalcemic efficacy. J Control Release 2006;114:334-42.

2. Ohara T, Kitamura S, Kitagawa T, Terada K. Dissolution mechanism of poorly water-soluble drug from extended release solid dispersion system with ethylcellulose and hydroxypropylmethylcellulose. Int J Pharm 2005;302:95-102.

3. Dhirendra K, Lewis S, Udupa N, Atin K. Solid dispersions: A review. Pak J Pharm Sci 2009;22:234-46.

4. Amidon GL, Lennernäs H, Shah VP, Crison JR. A theoretical basis for a biopharmaceutic drug classification: The correlation of in vitro drug product dissolution and in vivo bioavailability. Pharm Res 1995; 12:413-20.

5. Ad Noyes AA, Whitney WR. The rate of solution of solid substances in their own solutions J Am Chem Soc 1897;19:930-4.

6. Kapoor B, Kaur R, Kaur S. Solid dispersion: An evolutionary approach for solubility enhancement of poorly water soluble drugs. Int J Rec Adv Pharm Res 2012;2:1-16.

7. Lim SM, Pang ZW, Tan HY, Shaikh M, Adinarayana G, Garg S, et al. Enhancement of docetaxel solubility using binary and ternary solid dispersion systems. Drug Dev Ind Pharm 2015;41:1847-55.

8. Akiladevi D, Shanmugapandiyan P, Jebasingh D, Basak S. Preparation and evaluation of paracetamol solid dispersion technique. Int J Pharm Pharm Sci 2011;3:188-91.

9. Kushwaha A, Prajapati SK, Sharma B. Comparative study of acyclovir solid dispersion for bioavailability enhancement. Am J Pharm Tech Res 2011;1:179-201.

10. Chiou WL, Riegelman S. Preparation and dissolution characteristics of several fast-release solid dispersions of griseofulvin. J Pharm Sci 1969;58:1505-10.

11. Kanig JL. Properties of fused mannitol in compressed tablets. J Pharm Sci 1964;53:188-92.

12. Levy G. Effect of particle size on dissolution and gastrointestinal absorption rates of pharmaceuticals. Am J Pharm Sci Support Public Health 1963;135:78-92.

13. Urbanetz NA. Stabilization of solid dispersions of nimodipine and polyethylene glycol 2000. Eur J Pharm Sci 2006;28:67-76.

14. More SD, Sontakke SB. Solubility enhancement of gliclazide by solid dispersion method. Asian J Pharm Clin Res 2013;6:91-8.

15. Khazaal MN, Tarik AA, Abd AV. Efficacy of combination solid dispersion technology on dissolution performance of nalidixic acid and cefdinir. Asian J Pharm Clin Res 2017;1:394-401.

16. Dannenfelser RM, He H, Joshi Y, Bateman S, Serajuddin AT. Development of clinical dosage forms for a poorly water soluble drug I: Application of polyethylene glycol-polysorbate 80 solid dispersion carrier system. J Pharm Sci 2004;93:1165-75.

17. Chauhan B, Shimpi S, Paradkar A. Preparation and evaluation of glibenclamide-polyglycolized glycerides solid dispersions with silicon dioxide by spray drying technique. Eur J Pharm Sci 2005;26:219-30. 
18. Mizuno M, Hirakura Y, Yamane I, Miyanishi H, Yokota S, Hattori M, et al. Inhibition of a solid phase reaction among excipients that accelerates drug release from a solid dispersion with aging. Int J Pharm 2005;305:37-51.

19. Verreck G, Decorte A, Heymans K, Adriaensen J, Cleeren D, Jacobs A, et al. The effect of pressurized carbon dioxide as a temporary plasticizer and foaming agent on the hot stage extrusion process and extrudate properties of solid dispersions of itraconazole with PVP-VA 64. Eur J Pharm Sci 2005;26:349-58.

20. Wagh KS, Kale SS, Patil SK, Mali KD. Design and evaluation of bilayer tablets of glimepiride and metformin hydrochloride with combination of hydrophilic and hydrophobic polymers by hot melt extrusion. Asian J Pharm Clin Res 2014;7:300-4.

21. Hasegawa S, Hamaura T, Furuyama N, Kusai A, Yonemochi E, Terada K, et al. Effects of water content in physical mixture and heating temperature on crystallinity of troglitazone-PVP K30 solid dispersions prepared by closed melting method. Int J Pharm 2005;302:103-12.

22. Yoshihashi Y. Estimation of physical stability of amorphous solid dispersion using differential scanning calorimetry. J Therm Anal Calorim 2006;85:689-92.

23. Sri A, Latha RK. Formulation and evaluation of zolpidem tartrate layered tablets by melt granulation technique for treatment of insomnia. Asian J Pharm Clin Res 2018;1:139-47.

24. Mohanty S. Dissolution enhancement of seroquel by solid dispersion techniques. Asian J Pharm Clin Res 2016;2016:284-7.

25. Pouton CW. Formulation of poorly water-soluble drugs for oral administration: Physicochemical and physiological issues and the lipid formulation classification system. Eur J Pharm Sci 2006;29:278-87.

26. Dixit ND, Niranjan SK. A review: Solid dispersion. World J Pharm Pharm Sci 2014;3:238-57.

27. Singh J, Walia M, Harikumar SL. Solubility enhancement by solid dispersion method: A review. J Drug Deliv Ther 2013;3:148-55.

28. van Drooge DJ, Hinrichs WL, Visser MR, Frijlink HW. Characterization of the molecular distribution of drugs in glassy solid dispersions at the nano-meter scale, using differential scanning calorimetry and gravimetric water vapour sorption techniques. Int $\mathrm{J}$ Pharm 2006;310:220-9

29. Eriksson HJ, Hinrichs WL, van Veen B, Somsen GW, de Jong GJ, Frijlink HW, et al. Investigations into the stabilisation of drugs by sugar glasses: I. Tablets prepared from stabilised alkaline phosphatase. Int J Pharm 2002;249:59-70.

30. Seo A, Schaefer T. Melt agglomeration with polyethylene glycol beads at a low impeller speed in a high shear mixer. Eur J Pharm Biopharm 2001;52:315-25.

31. Vilhelmsen T, Eliasen H, Schaefer T. Effect of a melt agglomeration process on agglomerates containing solid dispersions. Int $\mathrm{J}$ Pharm 2005;303:132-42.

32. Hohman MM, Shin M, Rutledge G, Brennera MP. Electrospinning and electrically forced jets. II. Applications. Phys Fluids 2001;13:2221-36.

33. Neamnark A, Rujiravanit R, Supaphol P. Electrospinning of hexanoyl chitosan. Carbohydrate polymers. Int J Pharm 2006;66:298-305.

34. Zhang W, Yan E, Huang Z, Wang C, Xin Y, Zhao Q, et al. Preparation and study of PPV/PVA nanofibers via electrospinning PPV precursor alcohol solution. Eur Poly 2007;43:802-97.

35. Taki S, Badens E, Charbit G. Controlled release system formed by supercritical anti-solvent coprecipitation of a herbicide and a biodegradable polymer. J Supercrit Fluids 2001;21:61-70.

36. Dohrn R, Bertakis E, Behrend O, Voutsas E, Tassios D. Melting point depression by using supercritical $\mathrm{CO}_{2}$ for a novel melt dipersionmicronization process. J Mol Liq 2007;131-2:53-9.

37. Rowe RC, Sheskey PJ, Quinn ME. Handbook of Pharmaceutical Excipients. $6^{\text {th }}$ ed. London: Pharmaceutical Press; 2009.

38. Fikentscher H, Herrle K. Polyvinylpyrrolidone. Mod Plast 1945; 23:157-218

39. Stubberud L, Arwidsson HG, Hjortsberg V, Graffner C. Watersolid interactions. III. Effect of glass transition temperature, tg, and processing on tensile strength of compacts of lactose and lactose/ polyvinyl pyrrolidone. Pharm Dev Technol 1996;1:195-204.

40. Kolter K, Flick D. Structure and dry binding activity of different polymers, including kollidon VA 64. Drug Dev Ind Pharm 2000;26:1159-65.

41. Coppens KA. Hypromellose, ethylcellulose, and polyethylene oxide use in hot melt extrusion. Pharm Technol 2005;30:62-70.

42. Yamashita K, Nakate T, Okimoto K, Ohike A, Tokunaga Y, Ibuki R, et al. Establishment of new preparation method for solid dispersion formulation of tacrolimus. Int J Pharm 2003;267:79-91.

43. Repka MA, McGinity JW. Influence of chlorpheniramine maleate on topical hydroxypropylcellulose films produced by hot-melt extrusion. Pharm Dev Technol 2001;6:297-304.

44. Chiou WL, Riegelman S. Pharmaceutical applications of solid dispersion systems. J Pharm Sci 1971;60:1281-302.

45. Vila-Jato JL, Blanco J, Alonso MJ. The effect of the molecular weight of polyethylene glycol on the bioavailability of paracetamol-polyethylene glycol solid dispersions. J Pharm Pharm 1986;38:126-8.

46. Shah NH, Lazarus JH, Sheth PR, Jarowski CI. Carboxymethylcellulose: Effect of degree of polymerization and substitution on tablet disintegration and dissolution. J Pharm Sci 1981;70:611-3.

47. Singh J. Effect of sodium carboxymethylcelluloses on the disintegration, dissolution and bioavailability of lorazepam from tablets. Drug Dev Ind Pharm 1992;18:375-83.

48. Dittgen M, Durrani M, Lehmann K. Acrylic polymers: A review of pharmaceutical applications. STP Pharm Sci 1997;7:403-37.

49. Nakamichi K. Method of Manufacturing Solid Dispersion. United States Patent No; 1994.

50. Sertsou G, Butler J, Hempenstall J, Rades T. Solvent change coprecipitation with hydroxypropyl methylcellulose phthalate to improve dissolution characteristics of a poorly water-soluble drug. J Pharm Pharmacol 2002;54:1041-7.

51. Black SN, Collier EA, Davey RJ, Roberts RJ. Structure, solubility, screening, and synthesis of molecular salts. J Pharm Sci 2007;96:1053-68.

52. Liao X, Krishnamurthy R, Suryanarayanan R. Influence of processing conditions on the physical state of mannitol - implications in freezedrying. Pharm Res 2007;24:370-6.

53. Zhang H, Yao M, Morrison RA, Chong S. Commonly used surfactant, tween 80, improves absorption of P-glycoprotein substrate, digoxin, in rats. Arch Pharm Res 2003;26:768-72.

54. Yadav PS, Kumar V, Singh UP, Bhat HR, Mazumder B. Physicochemical characterization and in vitro dissolution studies of solid dispersions of ketoprofen with PVP K30 and d-mannitol. Saudi Pharm J 2013;21:77-84.

55. Bunaciu AA, Udriştioiu EG, Aboul-Enein HY. X-ray diffraction: Instrumentation and applications. Crit Rev Anal Chem 2015;45:289-99.

56. Taylor LS, Zografi G. Spectroscopic characterization of interactions between PVP and indomethacin in amorphous molecular dispersions. Pharm Res 1997;14:1691-8.

57. De Meuter P, Rahier H, Van Mele B. The use of modulated temperature differential scanning calorimetry for the characterisation of food systems. Int J Pharm 1999;192:77-84.

58. Van Duong T, Van den Mooter G. The role of the carrier in the formulation of pharmaceutical solid dispersions. Part II: Amorphous carriers. Expert Opin Drug Deliv 2016;13:1681-94.

59. Qi S, Craig D. Recent developments in micro- and nanofabrication techniques for the preparation of amorphous pharmaceutical dosage forms. Adv Drug Deliv Rev 2016;100:67-84

60. Paudel A, Van den Mooter G. Influence of solvent composition on the miscibility and physical stability of naproxen/PVPK 25 solid dispersions prepared by cosolvent spray-drying. Pharm Res 2012;29:251-70.

61. Li C, Yu DG, Williams GR, Wang ZH. Fast-dissolving core-shell composite microparticles of quercetin fabricated using a coaxial electrospray process. PLoS One 2014;9:e92106.

62. Yousaf AM, Mustapha O, Kim DW, Kim DS, Kim KS, Jin SG, et al. Novel electrosprayed nanospherules for enhanced aqueous solubility and oral bioavailability of poorly water-soluble fenofibrate. Int $\mathrm{J}$ Nanomedicine 2016;11:213-21.

63. Craig DQ. The mechanisms of drug release from solid dispersions in water-soluble polymers. Int J Pharm 2002;231:131-44.

64. Gupta SS, Parikh T, Meena AK, Mahajan N, Vitez I, Serajuddin ATM, et al. Effect of carbamazepine on viscoelastic properties and hot melt extrudability of soluplus ${ }^{\circledR}$. Int J Pharm 2015;478:232-9.

65. Ghosh I, Vippagunta R, Li S, Vippagunta S. Key considerations for optimization of formulation and melt-extrusion process parameters for developing thermosensitive compound. Pharm Dev Technol 2012;17:502-10.

66. Shah S, Maddineni S, Lu J, Repka MA. Melt extrusion with poorly soluble drugs. Int J Pharm 2013;453:233-52.

67. Fule RA, Meer TS, Sav AR, Amin PD. Dissolution rate enhancement and physicochemical characterization of artemether and lumefantrine solid dispersions. Int J Drug Deliv 2012;4:95-106.

68. Papageorgiou GZ, Bikiaris D, Karavas E, Politis S, Docoslis A, Park Y, et al. Effect of physical state and particle size distribution on dissolution enhancement of nimodipine/PEG solid dispersions prepared by melt mixing and solvent evaporation. AAPS J 2006;8:E623-31.

69. Li B, Konecke S, Wegiel LA, Taylor LS, Edgar KJ. Both solubility 
and chemical stability of curcumin are enhanced by solid dispersion in cellulose derivative matrices. Carbohydr Polym 2013;98:1108-16.

70. Friesen DT, Shanker R, Crew M, Smithey DT, Curatolo WJ, Nightingale JA, et al. Hydroxypropyl methylcellulose acetate succinate-based spray-dried dispersions: An overview. Mol Pharm 2008;5:1003-19.

71. Agrawal AM, Dudhedia MS, Patel AD, Raikes MS. Characterization and performance assessment of solid dispersions prepared by hot melt extrusion and spray drying process. Int J Pharm 2013;457:71-81.

72. Paudel A, Worku ZA, Meeus J, Guns S, Van den Mooter G. Manufacturing of solid dispersions of poorly water soluble drugs by spray drying: Formulation and process considerations. Int J Pharm 2013;453:253-84.

73. Zhang J, Huang Y, Liu D, Gao Y, Qian S. Preparation of apigenin nanocrystals using supercritical antisolvent process for dissolution and bioavailability enhancement. Eur J Pharm Sci 2013;48:740-7.

74. Xu M, Zhang C, Luo Y, Xu L, Tao X, Wang Y, et al. Application and functional characterization of POVACOAT, a hydrophilic co-polymer poly(vinyl alcohol/acrylic acid/methyl methacrylate) as a hot-melt extrusion carrier. Drug Dev Ind Pharm 2014;40:126-35.

75. Zidan AS, Rahman Z, Sayeed V, Raw A, Yu L, Khan MA, et al. Crystallinity evaluation of tacrolimus solid dispersions by chemometric analysis. Int J Pharm 2012;423:341-50.

76. Modi A, Tayade P. Enhancement of dissolution profile by solid dispersion (kneading) technique. AAPS Pharm Sci Tech 2006;7:68

77. Biswal S, Sahoo J, Murthy PN, Giradkar RP, Avari JG. Enhancement of dissolution rate of gliclazide using solid dispersions with polyethylene glycol 6000. AAPS Pharm Sci Tech 2008;9:563-70.

78. Ali W, Williams AC, Rawlinson CF. Stochiometrically governed molecular interactions in drug: Poloxamer solid dispersions. Int $\mathrm{J}$ Pharm 2010;391:162-8.

79. Mehta S, Joseph NM, Feleke F, Palani S. Improving solubility of BCS class II drugs using solid dispersion. J Drug Deliv Ther 2014;4:7-13.

80. Micheli L, Radoi A, Guarrina R, Massaud R, Bala C, Moscone D, et al. Disposable immunosensor for the determination of domoic acid in shellfish. Biosens Bioelectron 2004;20:190-6. 